\title{
FILOGENIA DOS ANTHURIUM REPTANTES DA SEÇÃO UROSPADIX (ARACEAE)
}

\author{
Maryelle Vanilla de Abreu Cerqueira ${ }^{1}$; Karena Mendes Pimenta ${ }^{2}$ e Cassio van den \\ Berg $^{3}$ \\ 1. Bolsista PIBIC/CNPq, Graduando em Agronomia, Universidade Estadual de Feira de Santana, e-mail: \\ maryellevanilla@gmail.com \\ 2. Orientador, Departamento de Ciências Biológicas, Universidade Estadual de Feira de Santana, e-mail: \\ vcassio@gmail.com \\ 3. Doutoranda do Programa de Pós Graduação em Botânica, Co-orientadora, Departamento de Ciências \\ Biológicas, Universidade Estadual de Feira de Santana, e-mail: karenamendes@hotmail.com
}

PALAVRAS-CHAVE: Araceae, Anthurium, Sequenciamento de DNA

\section{INTRODUÇÃO}

A família Araceae é composta por 125 gêneros e 3525 espécies (Boyce \& Croat, 2016). Anthurium Schott é o maior gênero de Araceae com cerca de 1000 espécies neotropicais (Boyce \& Croat, 2015).

A filogenia realizada por Carlsen \& Croat (2013) utilizou representantes de todas as seções do gênero Anthurium, com dados de sequências de cloroplasto (trnStrnG, trnH-psbA, trnC-ycfo) e uma região nuclear (primeiro íntron do gene CHS). Nessa análise surgiu um clado que já havia chamado atenção de pesquisadores em outra filogenia específica, a da secção Urospadix realizada por Temponi (2006); este clado inclui as espécies A. bellum Schott, A. longipes N.E.Br., A. radicans K.Koch \& Haage, A. malyi Wied-Neuw e A. bromelicola Mayo \& L.P.Félix.

Todas as espécies do clado em questão possuem problemas de delimitação específica constatadas pela dificuldade de identificação com base em morfologia nos herbários. No estudo filogenético da Seção Urospadix de Temponi (2006) foi evidenciado um grupo menor com cinco sinapomorfias. Dentre elas o caule reptante é o de mais fácil visualização. Entretanto, outra espécie foi incluída nesse grupo, Anthurium bromelicola, apesar de apresentar caule tipo escandente. Dentre as demais espécies de Urospadix utilizadas nas análises, outras três possuem o caule reptante, porém não se agruparam nesse clado, que são $A$. loefgrenii Engl., $A$. marense K.Krause e $A$. maricense Nadruz \& Mayo. Outra espécie, A. raimundi também portadoras de caule reptante, foram publicadas posteriormente, e por isso não constam nessas análises filogenéticas (Temponi 2006; Carlsen \& Croat 2013). 
Análises moleculares mais criteriosas que envolvam todas as espécies reptantes de Anthurium da Seção Urospadix podem gerar informações valiosas quanto à taxonomia, ecologia, genética e evolução do grupo em questão. Assim, os estudos aqui desenvolvidos visaram gerar dados para o esclarecimento das relações evolutivas entre as espécies de Anthurium reptantes seção Urospadix.

\section{MATERIAL E MÉTODOS}

Todos os procedimentos foram conduzidos no Laboratório de Sistemática Molecular de Plantas (LAMOL), da Universidade Estadual de Feira de Santana (UEFS). Foram utilizadas as amostras de Anthurium: A. acutum N.E.Br., A. bellum, A. bromelicola subsp. bahiense Mayo \& L.P.Felix, e A. bromelicola subsp. bromelicola Mayo \& L.P.Felix, A. loefgrenii, A. longipes, A. malyi, A. marense K. Krause, A. maricense Nadruz \& Mayo, A. radicans e A. raimundii Mayo, Haigh \& Nadruz.

Coleta, extração e armazenamento de DNAs totais: As amostras foram coletadas em Sílica e extraídas segundo uma modificação do protocolo de Doyle \& Doyle (1987). Foi realizado um teste de eficiência de obtenção de DNA total, no qual dois tipos de extração foram avaliados. O primeiro protocolo foi com moagem manual no cadinho; o segundo utilizando moinho com esferas metálicas (Qiagen).

A conservação do DNA extraído foi feita a $-20{ }^{\circ} \mathrm{C}$.

\section{Protocolos de amplificação e sequenciamento e preparo das sequências para} filogenia e filogeografia. Para amplificação de regiões nucleares e plastidiais utilizaram-se os mesmos primers de Carlsen \& Croat (2013) (trnS-trnG, trnH-psbA e CHS), seguindo como base os protocolos já otimizamos em outros trabalhos (van den Berg et al., 2009). Foram realizados testes de temperatura com diferentes concentrações de DNA e efetuada limpeza das amostras que apresentaram bandas que foram posteriormente sequenciadas em um sequenciador automático ABI3130XL.

Análises filogenéticas. Uma análise Bayesiana com o programa MRBAYES 3.2.6 foi realizada utilizando uma matriz combinada com as sequências obtidas das três regiões de DNA. Foram adicionadas na matriz como grupo externo sequências de Anthurium gracile (Rudge) Lindl. obtidas do Genbank. 


\section{RESULTADOS E/OU DISCUSSÃO (ou Análise e discussão dos resultados)}

Foram extraídas 22 amostras de DNA de 11 espécies do gênero Anthurium, e a partir destas realizou-se 41 PCRs (Polymerase Chain Reaction), para amplificação de três regiões: $\operatorname{trnS}$-trnG, $\operatorname{trnH}-p s b A$ e CHS. A qualidade das amostras foi conferida através de eletroforese em géis de agarose. As amostras diluídas a 20× apresentaram melhores resultados, sendo esta concentração adotada como padrão para todas as regiões. As amostras extraídas manualmente apresentaram melhor quantidade de DNA total do que as feitas com o auxílio do moinho. Das amostras do estudo, foi possível obter sequências satisfatórias de nove, que foram utilizadas para a análise combinada das sequências da árvore da Figura 1. Não foi possível obter sequências de A. acutum, A. queirozianum e A. raimundii.

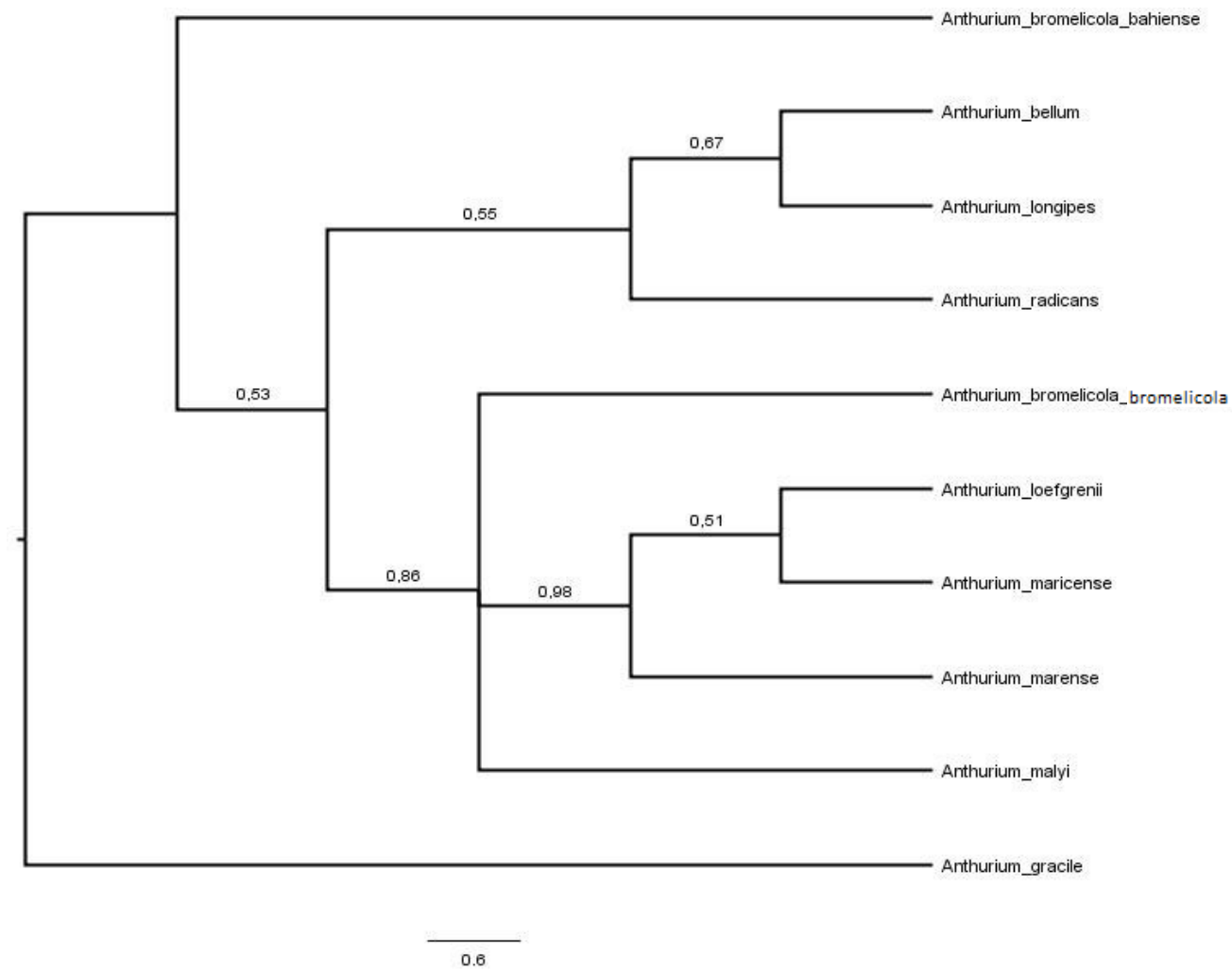

Figura 1: Árvore Bayesiana de espécies selecionadas de Anthurium gerada a partir de sequências das regiões de plastídeo $p s b A$-trnH e $\operatorname{trnS}$-trnG e nuclear CHS. Os valores correspondem às probabilidades posteriores de cada clado, a barra inferior corresponde ao número de mutações esperadas.

$\mathrm{Na}$ árvore obtida detectamos a presença de três grupos. O primeiro corresponde apenas a A. bromelicola subsp. bahiense como irmão do restante (PP 0.53), o segundo a A.bellum + A.longipes + A.radicans (PP 0.55), e o terceiro A. bromelicola subsp. bromelicola + A. loefgrenii + A. maricense + A. marense + A. malyi (PP 0.86). Com base 
nos dados gerados, foi possível constatar que as subespécies A. bromelicola subsp. bahiense Mayo \& L.P.Felix e A. bromelicola subsp. bromelicola Mayo \& L.P.Felix ficaram posicionadas em grupos diferentes da árvore, demonstrando que podem não pertencer à mesma espécie. Entretanto os suportes para o primeiro e segundo grupos mencionados foram baixos, indicando a necessidade de estudos morfológicos e populacionais para verificar esse padrão, bem como mais dados de outras regiões de DNA.

\section{CONSIDERAÇÕES FINAIS (ou Conclusão)}

A utilização de sequências de apenas três regiões de plastídeo e núcleo geraram uma árvore, porém os suportes para os diferentes clados foram inerentemente baixos, indicando uma quantidade de variação ainda insuficiente para a reconstrução filogenética das amostras incluídas no estudo. Isso indica a necessidade de incluir mais regiões e também fazer estudos complementares para avaliar a circunscrição de $A$. bromelicola.

\section{REFERÊNCIAS}

Boyce, P. C. \& Croat, T. B. (2015). The Überlist of Araceae, Totals for Published and Estimated Number of Species in Aroid Genera. Disponível em: <http://www.aroid.org/genera/140601uberlist.pdf>. Acesso em: 15 Jul 2018.

Boyce, P.C., Croat T. (2016). The Überlist of Araceae - totals for published and 19 estimated number of species in Aroid genera. Disponível em: <http://www.aroid.org/genera/160330uberlist.pdf>. Acesso em: 15 Jul 2018.

Carlsen, M.M. \& Croat, T.B. (2013). A molecular phylogeny of the species-rich neotropical genus Anthurium (Araceae) based on combined chloroplast and nuclear DNA. Systematic Botany 38: 576-588.

Doyle, J. J. \& Doyle, J. L. (1987). A rapid DNA isolation procedure for small quantities of fresh leaf tissue. Phytochem Bull 19: 11-15.

Temponi, L.G. (2006). Sistemática de Anthurium sect. Urospadis (Araceae). Tese de Doutorado - Instituto de Biociências da Universidade de São Paulo, São Paulo, Brasil. van den Berg, C. Higgins, W. E., Dressler, R. L., Whitten, W. M., Soto-Arenas, M. A., \& Chase, M. W. (2009). A phylogenetic study of Laeliinae (Orchidaceae) based on combined nuclear and plastidDNA sequences. Annals of Botany104: 417-430. 